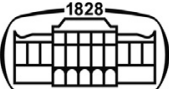

AKADÉMIAI KIADÓ

Journal of Behavioral Addictions

9 (2020) 4, 967-977

DOI:

$10.1556 / 2006.2020 .00102$

(c) 2020 The Author(s)

\title{
A daily diary investigation on the job-related affective experiences fueled by work addiction
}

\section{CRISTIAN BALDUCCI ${ }^{1 *} \odot$, PAOLA SPAGNOLI ${ }^{2}$, LORENZO AVANZI $^{3}$ and MALISSA CLARK ${ }^{4}$}

\author{
${ }^{1}$ Department of Psychology; University of Bologna, Viale Berti Pichat, 5, 40127 Bologna, Italy \\ ${ }^{2}$ Department of Psychology, University of Campania “Luigi Vanvitelli”, Viale Ellittico, 31, 81100 \\ Caserta, Italy \\ ${ }^{3}$ Department of Psychology and Cognitive Science, University of Trento, Corso Bettini, 31, 38068 \\ Rovereto, Trentino, Italy \\ ${ }^{4}$ Department of Psychology, University of Georgia, 125 Baldwin Street, 30602, Athens, GA, USA
}

Received: May 4, 2020 • Revised manuscript received: October 14, 2020; November 30, 2020 - Accepted: December 5, 2020 Published online: December 30, 2020

\section{FULL-LENGTH REPORT}

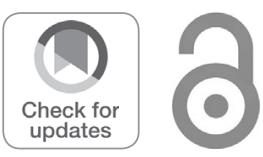

* Corresponding author.

E-mail: cristian.balducci3@unibo.it

\begin{abstract}
Background and aims: We studied the quality of the job-related emotional experiences associated with work addiction. We hypothesized that work addiction would fuel both a higher level of daily job-related negative affect and a lower level of daily job-related positive affect and that such affective experiences would mediate the relationship between work addiction and emotional exhaustion reported at the end of the working day. Additionally, in light of typical behaviors and cognitions associated with work addiction, we also hypothesized that work addiction would modify the relationships between day workload and same day emotional strain reactions (i.e., job-related negative affect and job-related positive affect). Methods: Participants were 213 workers (42.5\% female), most of whom holding a high-profile job position, who were followed for 10 consecutive working days in the context of a daily diary study. Results: Multilevel analyses controlling for neuroticism revealed that work addiction was uniquely and positively related to daily job-related negative affect and that the latter mediated the relationship between work addiction and daily emotional exhaustion. On the other hand, work addiction was not negatively related to daily job-related positive affect; this relationship emerged only when removing neuroticism from the model. Additionally, work addiction strengthened the relationship between day workload and day job-related negative affect. Discussion: Results indicate that work addicted are characterized by the experience of a negatively connotated affect during work, and that this kind of affect may be a mechanism explaining the work addiction-burnout relationship.
\end{abstract}

\section{KEYWORDS}

work addiction, excessive work investment, compulsive work, job-related affect, daily diary research

In the last decade there has been increasing attention towards the phenomenon of work addiction - a behavioral addiction characterized by a persistent and dysfunctional form of heavy work investment potentially leading to clinically relevant negative consequences (Andreassen, 2014; Andreassen, Schaufeli, \& Pallesen, 2018; Atroszko, Demetrovics, \& Griffiths, 2020; Brevers \& Noel, 2015; Griffiths, Demetrovics, \& Atroszko, 2018; Griffiths \& Karanika-Murray, 2012; Ng, Sorensen, \& Feldman, 2007; Schaufeli, Taris, \& Bakker, 2008; Sussman, 2018).

According to a recent proposal for reaching a consensus on the clinical definition of the phenomenon, the central feature of work addiction is "a compulsion to work and preoccupation with work activities leading to significant harm and distress of a functionally impairing nature to the individual and/or other significantly relevant relationships (friends, family). The behavior is characterized by the loss of control over the working activity and persists over a significant period of time" (Atroszko, Demetrovics, \& Griffiths, 2019, p. 9). Such definition is coherent with results emerging from organizational studies that have 
identified two central aspects of work addiction (also termed workaholism in the field), that is, working compulsively and working excessively - well beyond what is reasonably expected of the individual - even in the face of adverse psychological and psychosocial outcomes (e.g., Avanzi, Perinelli, Vignoli, Junker, \& Balducci, 2020; Balducci, Avanzi, \& Fraccaroli, 2018; Clark, Michel, Zhdanova, Pui, \& Baltes, 2016; Spagnoli, Balducci, Fabbri, Molinaro, \& Barbato, 2019).

Despite undeniable advances in the definition of work addiction, a number of ambiguities still surround the phenomenon (e.g., Clark et al., 2016; Griffiths et al., 2018) and one such ambiguity concerns the emotional valence associated with the job in work addiction. What is not clear is whether work addicted experience joy and satisfaction while working - perhaps this explaining why they work for so excessively at the expense of other activities - or, rather, emotional uneasiness, that is, negative emotions and affect. On this there has been much debate with opposing viewpoints (see, e.g., Ng et al., 2007; Taris, Van Beek, \& Schaufeli, 2014), but only few convincing empirical studies. Although according to some (Andreassen et al., 2018) understanding the job-related affective experiences in work addiction may be irrelevant for a characterization of the phenomenon, we disagree with such a view for a number of reasons. First, uncovering such experiences may help to better qualify the peculiarities of work addiction when compared to related constructs such as work passion (Vallerand, Houlfort, \& Forest, 2014) and work engagement (Taris et al., 2014), which are characterized by an affective component of enthusiastic enjoyment for the job. Additionally, understanding the job-related affect in work addiction may also help to clarify the mechanism leading to the stress-related negative outcomes that work addicted frequently report (see Clark et al., 2016). Indeed, the existence of affective-based strain processes has been well documented (e.g., Meier \& Cho, 2018) with affective experiences being at the core of the stress process (Lazarus, 2006).

Therefore, the main aims of the present study are to examine the job-related affective experiences in work addiction and explore whether such experiences may explain the link between work addiction and emotional exhaustion a crucial component of burnout, that is, one of the most studied work-related health outcome of work addiction (see Clark et al., 2016).

\section{THEORETICAL FRAMEWORK AND HYPOTHESES}

While most researchers agree that work addicted are pervaded by negative emotions such as anxiety and guilt when they are not working (Clark, Smith, \& Haynes, 2020; $\mathrm{Ng}$ et al., 2007; Porter, 1996), there is a substantial lack of consensus regarding the emotional experiences of work addicted while at work. According to some (Baruch, 2011; Ng et al., 2007; Peiperl \& Jones, 2001) when work addicted pursue the activity which is central to their life, they experience positive moods and affect. For example, Bonebright, Clay, and Ankenmann (2000) related work addiction to the "immense enjoyment" experienced while working. Others (e.g. Spence \& Robbins, 1992; Taris et al., 2014), argued that true work addicted do not enjoy their work and even when they work they tend to experience negative emotions such anger, anxiety and resentment. Still others (Snir \& Harpaz, 2012) proposed that work addicted more frequently experience both positive (pleasure) and negative (frustration) mood states while at work.

The meta-analysis by Clark et al. (2016) was unable to draw a conclusive picture on this question. They found a positive and moderate relationship between work addiction and work enjoyment. At the same time, however, work addiction was negatively related, although to a lesser degree, with job satisfaction. Furthermore, work addiction was significantly and positively related with negative affectivity (trait and state) and it was not related with positive affectivity (trait or state). Clark et al. postulated that the negative affect that pervades work addicted when they are not at work outweighs the positive one that they may experience at work (Clark et al., 2016). More recent studies also reported inconclusive results. For example, Balducci et al. (2018) found that work addiction was related to negative job-related affect, while Kirrane, Breen, \& O'Connor (2017) - in a qualitative investigation - found that work addicted report higher levels of job satisfaction, a finding corroborated by coworkers. Overall, it is clear that there is a need for further research to clarify the work-related affective experiences of work addicted.

We argue that, since work addicted invest much time and effort in work-related activities (see Snir \& Harpaz, 2012) they frequently experience the activation of the stress response including sympathetic arousal and load (or strain) reactions (Mejman \& Mudler, 1998). Strain reactions have affective correlates, since emotions are fundamental components of the stress experience. According to allostatic load theory (see Ganster \& Rosen, 2013), negative emotions such as anger, tension, anxiety, and depression are among the first symptoms of stress. Additionally, although studies have often investigated negative affective states and mood responses to stress, research has confirmed the existence of positive affective responses that are relatively independent from the negative ones (e.g., Totterdel \& Niven, 2014; Van Katwyk, Fox, Spector, and Kelloway, 2000). For example, Van Eck, Nicolson, and Berkhof (1998) found that stressors lead to a decrease in positive affect as well as an increase in negative affect.

Thus, building on the above, we argue that during working days, as a consequence of a heavy and excessive work investment, work addicted find themselves in a condition of emotional strain characterized by the experience of higher levels of job-related negative affect and lower levels of job-related positive affect. We postulate that an important reason for the inconclusive findings emerging from previous research is related to the sub-optimal research designs adopted, which was frequently cross-sectional in nature (see Andreassen et al., 2018; Clark et al., 2016). Such an approach 
is inadequate to capture fluctuating phenomena such as affective states and is strongly contaminated by trait affect (Kaplan, Dalal, \& Luchman, 2013) and retrospective memory biases (Gabriel et al., 2018). Given their transient nature, affective states are better captured by asking people to indicate their feelings over a short time interval, such as the past 24 hours (Kaplan et al., 2013). Such an approach has rarely, if at all, been used in work addiction research. Additionally, previous research has often investigated a single facet of job-related affect experienced in work addiction, such as joy (e.g., Spence \& Robbins, 1992) or satisfaction (Schaufeli, Taris, \& van Rhenen, 2008); thus failing to gain a more complete picture of the job-related affective experiences of work addicted.

By collecting affective experiences using a daily diary carried out during working days and by simultaneously focusing on negative and positive job-related affect, the present study addresses important limitations of previous research. In line with our theoretical arguments proposed above, we hypothesized that:

Hypothesis 1: Work addiction is positively related to the average level of daily job-related negative affect across days ${ }^{1}$.

Hypothesis 2: Work addiction is negatively related to the average level of daily job-related positive affect across days.

Additionally, we considered that the hypothesized configuration of daily affective experiences fueled by work addiction has fatigue after-effects at the end of the working day. A particular form of fatigue is emotional exhaustion (see Geurts \& Sonnentag, 2006) - a significant lack of energy and the feeling that one's emotional resources have been used up (Maslach \& Jackson, 1984). Emotional exhaustion is the first emerging component of burnout (Lee \& Ashforth, 1996) - a very prevalent phenomenon among workers (see Atroszko et al., 2020). Previous research has frequently investigated the relationship between work addiction and burnout symptoms. For example, a Japanese study by Shimazu, Schaufeli, Kamiyama, and Kawakami (2015) found that work addiction fueled job stress symptoms including tiredness and fatigue and similar results were also found repeatedly by others (e.g., Avanzi et al., 2020; Hakanen, Peeters, \& Schaufeli, 2018; Nie \& Sun, 2016). A meta-analysis concluded that the (positive) relationship between work addiction and burnout is well-established and moderately strong (Clark et al., 2016). However, what has been less investigated is how (i.e., the mechanism by which) work addiction may lead to exhaustion and burnout. A previous study by Schaufeli, Bakker, van der Heijden, and Prins (2009) found that this may happen via role conflict situations (e.g., work-family conflict), which may be significantly fueled by work addiction. A part from this study, however,

\footnotetext{
${ }^{1}$ A stable personal characteristic such as work addiction can only predict the average level of outcomes showing variation at the day level, such as-in our case-the two forms of daily job-related affect. (See the data analysis section below for further details).
}

the topic remains substantially underexplored. Thus, by building on the idea that that work addiction may lead to a peculiar constellation of job-related affective experiences (see our first two hypotheses above), we further hypothesized that job-related affect may constitute a mechanism linking work addiction to emotional exhaustion.

Although negative affective states have received more attention in connection to stress-related disorders including burnout (see Ganster \& Rosen, 2013), research has found that positive affective states contribute significantly, over and above their negative counterpart, to burnout signs and symptoms (see Thoresen, Kaplan, Barsky, Warren, and de Chermont, 2003). Thus, we expected that work addiction, by fueling higher levels of job-related negative affect and lower levels of job-related positive affect, indirectly influence emotional exhaustion as experienced at the end of the working day.

Hypothesis 3: Daily job-related negative affect mediates the positive relationship between work addiction and the average level of daily emotional exhaustion across days.

Hypothesis 4: Daily job-related positive affect mediates the positive relationship between work addiction and the average level of daily emotional exhaustion across days.

Finally, we investigated the potential role that work addiction, acting as an individual vulnerability factor, may play in the relationship between a common workplace stressor and strain. To explore this role, we chose to focus on workload because it is a prominent stressor in the modern workplace (see Reid \& Ramarajan, 2016) and a powerful predictor of job-related affective well-being and stress outcomes such as burnout (e.g., Ilies, Dimotakis, \& Pater, 2010). Higher levels of workload may be particularly problematic for work addicted since work addiction has been found to be related with obsessive compulsive disorder and adult attention deficit hyperactivity disorder (Andreassen, Griffiths, Sinha, Hetland, \& Pallesen, 2016), which include symptoms such as poor organization, obsessiveness and rigid perfectionism (see also Atroszko et al., 2020; Clark, Lelchook, \& Taylor, 2010; Spagnoli et al., 2020). Such symptoms do not help in dealing effectively with high workload and actually may lead to the accentuation of the strain reactions associated with workload. Therefore, we further hypothesized that:

Hypothesis 5: Work addiction strengthens the positive relationship between daily workload and daily job-related negative affect.

Hypothesis 6: Work addiction strengthens the negative relationship between daily workload and daily job-related positive affect.

We tested the proposed hypotheses by following a sample of workers for ten consecutive working days. We measured work addiction with a preliminary survey, while we measured workload, affective well-being and emotional exhaustion at the end of each working day by using the 
diary. Additionally, we controlled for neuroticism, which in some studies has been found to correlate with work addiction (Balducci et al., 2020; Clark et al., 2010) and is a powerful predictor of affective states (Thoresen et al., 2003), stress and burnout (Maslach, Schaufeli, \& Leiter, 2001).

\section{METHOD}

\section{Participants and procedure}

A heterogeneous sample of participants with a standard working week was recruited by targeting occupations with potentially high levels of work addiction (see Taris, Van Beek, \& Schaufeli, 2012): self-employed workers, managers, entrepreneurs, and employees holding a responsibility position in their organization. Participants were contacted among acquaintances of the researchers and by means of snowball sampling. They were invited to take part in a paper and pencil daily diary study on work-related well-being. Participation was on a voluntary basis. A sample of 213 workers took part in the study. There were some refusals (less than $5 \%$ of the final sample - 10 cases) with the main reason for not participating being the low interest for the nature of the study. The number of refusals could be recorded because when a participant suggested the name of a new potential participant, the latter was approached by the researchers. Participants first completed a preliminary questionnaire, followed by an end of working day questionnaire for ten consecutive working days (i.e., the diary study period). Person-level variables were derived from the preliminary questionnaire, while day-level variables were derived from the diary questionnaire. The preliminary and the 10 diary questionnaires were given all together to participants by including them in a survey pack, with the instruction to seal the pack and return it to the researchers at the end of the diary study period. To protect anonymity, the questionnaires and the pack didn't contain identifying information. Once returned, the survey pack was included in a box with other survey packs following standard procedures to manage research data and later questionnaire responses were digitalized for the analyses. To reinforce compliance, the researchers carefully explained to participants how to fill in the daily surveys, emphasizing the importance of completing them at the end of the working day and for the agreed series of consecutive days. Participants were females in $42.5 \%$ of the cases and had a mean age of 45.5 years (SD $=10.4$ ). They had mostly completed university education $(50.4 \%)$ and were entrepreneurs or self-employed (46.4\%), managers $(14.5 \%)$, and employees in the remaining cases. Additionally, they mostly worked in the private sector $(80.7 \%)$, and the average number of working hours in a typical day was $8.4(\mathrm{SD}=1.9)$.

\section{Person-level variables}

Work addiction was measured by using the 10-item Italian validated version (Balducci, Avanzi, Consiglio, Fraccaroli, \& Schaufeli, 2017) of the Dutch Work Addiction Scale
(DUWAS; Schaufeli, Shimazu, \& Taris, 2009). The DUWAS investigates the respondent's feelings about his/her work, which reflect the two components of work addiction (i.e., working compulsively [WC] and working excessively [WE]). Example items are the following: "I feel that there's something inside me that drives me to work hard" (WC) and "I stay busy and keep many irons in the fire" (WE). Responses are given on a 4-point scale varying from 1 ("Never or almost never") to 4 ("Almost always or always"). Cronbach's alpha for the overall scale was 0.80 . For the analyses we derived the WE and WC subscale scores and used them as manifest indicators of the work addiction latent construct. ${ }^{2}$

Neuroticism was measured with four items derived from the Italian version (Flebus, 2015) of a big-five personality inventory included in the International Personality Item Pool (IPIP; Goldberg, 1999). An example item is "I get stressed out easily". Responses to items varied from 1 ("It does not describe me at all") to 5 ("It describes me completely"). Cronbach's alpha was 0.82 . For the analyses, we used two-item parcels as indicators of the corresponding latent construct.

\section{Day-level variables}

Day job-related negative affect and day job-related positive affect were assessed with four items each derived from a shortened and adapted version of the Job-related Affective Well-being Scale (JAWS; Van Katwyk et al., 2000). The scale was adapted in Italian by using the back translation method and used a number of times in previous research on jobrelated affect (e.g., Balducci, Cecchin, Fraccaroli, \& Schaufeli, 2012). Participants were asked how much did they feel any of eight different positive and negative affective states during the working day, with responses given on a 5-point scale ranging from 1 ("not at all") to 5 ("very much"). The negative affective states assessed were anger, anxiety, pessimism, and discouragement (average Cronbach's $\alpha$ across the ten working days: 0.90; range: 0.88-0.94), while the positive states were satisfaction, calmness, enthusiasm, and energy (average Cronbach's $\alpha$ : 0.85 ; range: $0.81-0.87$ ). For the analyses, we used two item parcels for each affective dimension.

Day emotional exhaustion was investigated by adapting two items from the Copenhagen Burnout Inventory (CBI Kristensen, Borritz, Villadsen, \& Christensen, 2005; Italian version by Avanzi, Balducci, \& Fraccaroli, 2013). Participants were asked to think how they felt when completing the survey (i.e., at the end of the working day), with an example item being "I feel emotionally exhausted". Responses were collected on a 5-point scale ranging from 1 ("not at all") to 5 ("very much"). The average Cronbach's alpha for this measure was 0.85 (range: $0.79-0.89$ ). The items were used as indicators of the emotional exhaustion latent construct.

Day workload was measured by adapting three items (e.g., "Today, I had to work very fast") from the Job Content Questionnaire (Baldasseroni et al., 2001; Karasek et al., 1998;

${ }^{2}$ The two subscales were strongly intercorrelated in the present study $(\mathrm{r}=0$. 64; $P<0.001)$. 
Italian approved and validated version by). Responses were given on a 5-point scale varying from 1 ("strongly disagree") to 5 ("strongly agree"). The average Cronbach's alpha obtained was 0.89 (range: 0.84-0.93). For the analyses the three items were used as indicators of the day workload latent construct.

\section{Data analysis}

To test the hypotheses we conducted multilevel structural equation modeling (MSEM). The tested model was a so-called 2-1-1 model (see Preacher, Zhang, \& Zyphur, 2011) with the main independent variable (work addiction) being at level 2 ('between' or person level) and the mediators (i.e., job-related negative affect and job-related positive affect) and the dependent variable (i.e., emotional exhaustion) being at level 1 ('within' or day level). We adopted MSEM since it is superior to standard multilevel modeling when applied to mediation analysis (MacKinnon, 2008; Preacher et al., 2011).

In a mediation model involving a level 2 variable, as in our case, only the 'between' indirect effect is present (see Preacher et al., 2011, p. 167). From this it follows that the only estimation of interest for testing the hypothesized mediation is the product of the 'between' path coefficients. Thus, Hypotheses 1 and 3 tested, respectively, whether work addiction affected the average level of daily job-related negative affect in the observation period of ten days and whether, in the said observation period, the average level of daily job-related negative affect mediated the relationship between work addiction and the average level of emotional exhaustion experienced at the end of the working day. Hypotheses 2 and 4 tested parallel main and mediating 'between' relationships, respectively, with job-related positive affect in place of its negative counterpart. Regarding Hypotheses 5 and 6 , work addiction could moderate the between and/or the within (see Preacher, Zhang, \& Zyphur, 2016) relationships between day workload, on the one hand, and the day job-related negative and positive affect variables, on the other hand. We focused on the moderation of the 'between' relationships, which is in line with the 'between' nature of Hypotheses 1-4. Model fit was assessed according to the following criteria: $\chi^{2}$ likelihood ratio statistic, Comparative Fit Index (CFI), Tucker-Lewis Index (TLI), the Root Mean Square Error of Approximation (RMSEA) and Standardized Root Mean Square Residual (SRMR). The critical value of chi-square is sensitive to large sample sizes and easily produces a statistically significant result (Kline, 2016). We accepted TLI and CFI values greater than 0.90 (Bentler, 1990), and RMSEA and SRMR values lower than 0.08 (Browne \& Cudeck, 1993; Hu \& Bentler, 1999). The main analyses were conducted with Mplus 7.4 (estimation method: Robust Maximum Likelihood).

\section{Ethics}

The research was conducted in accordance with the Helsinki Declaration. The IRB of the University of Campania "L. Vanvitelli" (Italy) approved the study. All subjects were informed about the study, including that they could withdraw at any time, and all provided informed consent.

\section{RESULTS}

\section{Descriptive statistics and preliminary analyses}

Table 1 reports the descriptive statistics and correlations between the main study variables. Work addiction showed a positive and significant correlation with neuroticism $(r=0.42 ; P$ $<0.001)$. Moreover, it was also positively related with daily workload $(r=0.49 ; P<0.001)$, number of hours worked in a typical day $(r=0.30 P<0.001)$, daily negative affect $(r=0.42 ; P$ $<0.001)$, and daily emotional exhaustion $(r=0.49 ; P<0.001)$.

We then examined the Intraclass Correlation Coefficient (ICC) for each daily level variable. The ICC varied from 0.38 to 0.56 , indicating the appropriateness of a multilevel approach to hypotheses testing.

\section{Tests of main and mediating 'effects' (Hypotheses 1- 4)}

MSEM analyses indicated that the hypothesized model (see Fig. 1) fit the data quite well: $\chi^{2}(97)=247.22, P<0.001$; $\mathrm{CFI}=0.98$; TLI $=0.96$; RMSEA $=0.027$; $\mathrm{RMSR}_{\text {daily level }}$ $=0.030 ; \mathrm{RMSR}_{\text {person level }}=0.075$. All the observed variables loaded strongly on the respective latent construct $\left(\geq 0.75^{3}\right)$. At the between level (see Fig. 1), work addiction was positively related to daily job-related negative affect $(0.26, t=$ 2.54, $P<0.05)$, but it was not related to daily job-related positive affect $(-0.17, t=-1.52, \mathrm{~ns})$. These results provided support for Hypothesis 1, but not for Hypothesis 2. Thus, individuals with stronger work addiction reported a higher average level of daily job-related negative affect during the observation period of 10 days. However, work addiction was unrelated to average levels of daily job-related positive affect during the same period.

Daily job-related negative affect was positively related to daily exhaustion at the between $(0.29, t=3.18, P<0.01)$ and within levels $(0.23, t=4.95, P<0.001)$. On the contrary, daily job-related positive affect did not relate to day emotional exhaustion either at the between $(0.08, t=1.00$, $\mathrm{ns})$ or within level $(-0.01, t=-0.30$, ns). Given these results, only a test of the mediating role of daily job-related negative affect on the relationship between work addiction and daily emotional exhaustion made sense. Such a test provided evidence of significance (unstandardized estimate: $0.13, \mathrm{t}=2.11, P<0.05$, 95\% CI: 0.010-0.242), supporting Hypothesis 3. On the other hand, Hypothesis 4, regarding the mediating role of daily job-related positive affect on the relationship between work addiction and daily emotional exhaustion, was not supported.

\section{Testing the moderating 'effects' (Hypotheses 5-6)}

We then tested for the moderating role of work addiction in the relationships between day workload and job-related affect. Regarding Hypothesis 6, it was already clear that it could not be supported by the analyses, since at the between

${ }^{3}$ Unless otherwise stated, standardized estimates are reported. 


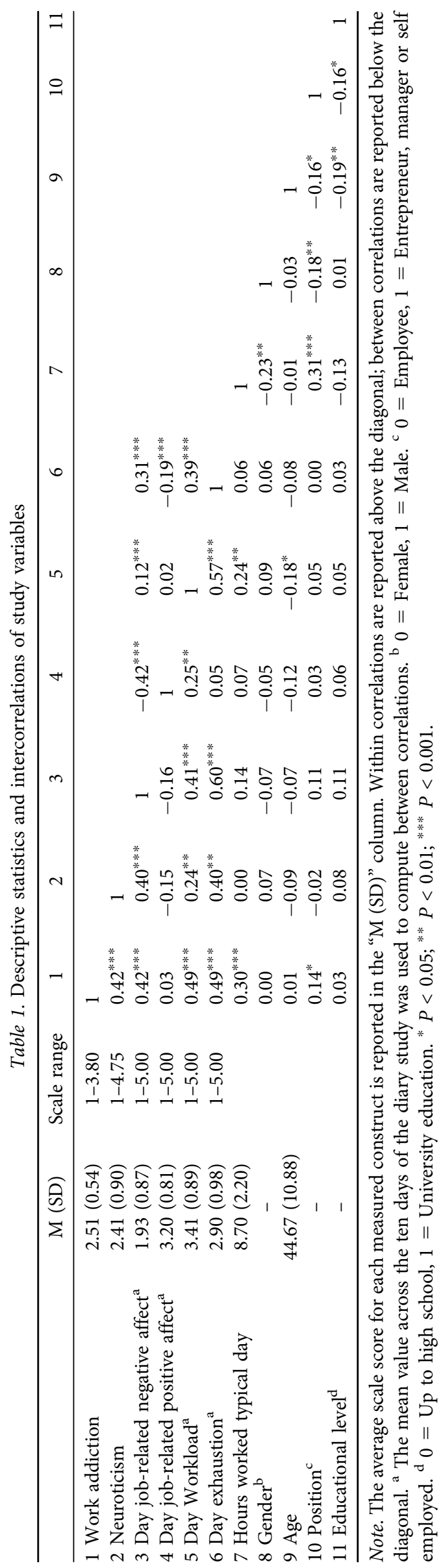

level (see Fig. 1) day workload was not negatively related to day job-related positive affect, as implicated by the hypothesis. Despite this, we examined also the potential moderating role of work addiction in the relationship between day workload and day job-related positive affect, since results could reveal unexpected affective implications of work addiction. To proceed, we modeled an interaction between latent variables (i.e., day workload and work addiction) in the 'between' part of a simplified version of the tested model. This simplified model only included work addiction, day workload, neuroticism, day job-related negative affect and day job-related positive affect. We tested the two moderating paths implicated by Hypotheses 5 and 6 in parallel by conducting a -2 Log likelihood difference test to compare the fit of the model that did not include any interaction path (i.e., baseline model), with the fit of the model that included the two interaction paths (i.e., interaction model) (see Klein \& Moosbrugger, 2000). The values of the resulting $\mathrm{D}$ statistic are approximately distributed as $\chi^{2}$, with the degrees of freedom to determine the significance of $\mathrm{D}$ calculated by subtracting the number of free parameters in the baseline model from the number of free parameters in the interaction model. Fit indices are not available for moderated MSEM (see Maslowsky, Jager, \& Hemken, 2015). However, a preliminary test of the baseline model showed that the model fit sufficiently well the data $\left(\chi^{2}(48)=\right.$ 166.21, $P<0.001$; CFI $=0.97$; TLI $=0.96$; $\mathrm{RMSEA}=0.034$; $\mathrm{SRMR}_{\text {within level }}=0.037$; $\mathrm{SRMR}_{\text {between level }}=0.055$ ). For the moderation tests, the baseline and the interaction models were estimated by using the option "algorithm = integration" in Mplus (see Muthen \& Muthen, 2015). The baseline model produced a -loglikelihood value of $-16,811.52$ with 53 free parameters. When we included the between paths from the work addiction by day workload interaction to day job-related negative and positive affect variables, we obtained a model -loglikelihood of $-16,808.42$ with 55 free parameters. The resulting $D$ was $6.20(\Delta \mathrm{n}$. of free parameters $=2)$, suggesting that the interaction model fit significantly better than the baseline model $(P<0.05)$. The path from the interaction to day job-related negative affect was significant $(0.23, \mathrm{t}=2.106, P<0.05,95 \%$ C.I. $=0.016-$ 0.446 ), indicating that only for individuals with stronger work addiction tendencies, a higher average level of day workload during the observation period of 10 days was related with a higher average level of day job-related negative affect (see Figs. 2 and 3), which supported Hypothesis 5. On the contrary, the path from the interaction to day job-related positive affect (related to Hypothesis 6) was not significant.

\section{Supplemental analyses}

In a post-hoc analysis (not reported here), we refit the model represented in Fig. 1 without controlling for neuroticism. Results showed that work addiction was negatively and significantly related to average daily job-related positive affect $(P<0.01)$ and positively related to average daily jobrelated negative affect $(P<0.001)$. This suggested that the hypothesized relationship between work addiction and daily 


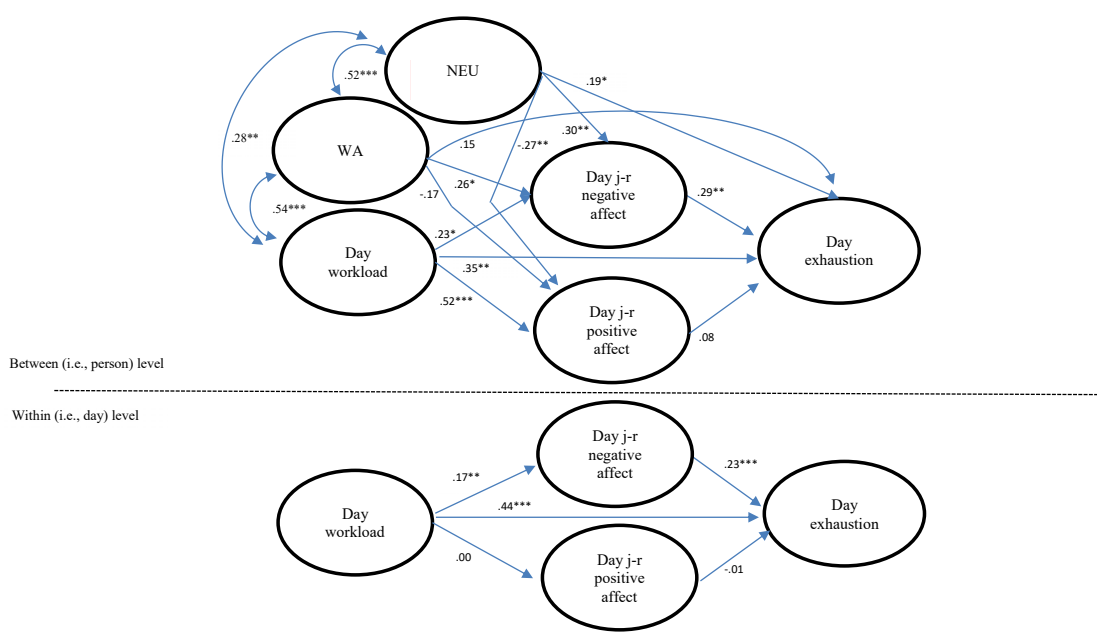

Fig. 1. The multilevel structural equation model analyzed to test Hypotheses 1-4.

Note. Standardized paths are reported. The latent correlation between day negative affect and day positive affect (not reported in figure) was $-0.59^{* * *}$ at the day-level, and $-0.22^{*}$ at the person level. Gender and hours worked in a typical day were also included as person-level covariates of day exhaustion. They didn't play a significant 'effect'. WA: Work addiction. NEU: Neuroticism. j-r: job-related.

$$
{ }^{*} P<0.05 ;{ }^{* *} P<0.01 \text {; ** } P<0.001
$$

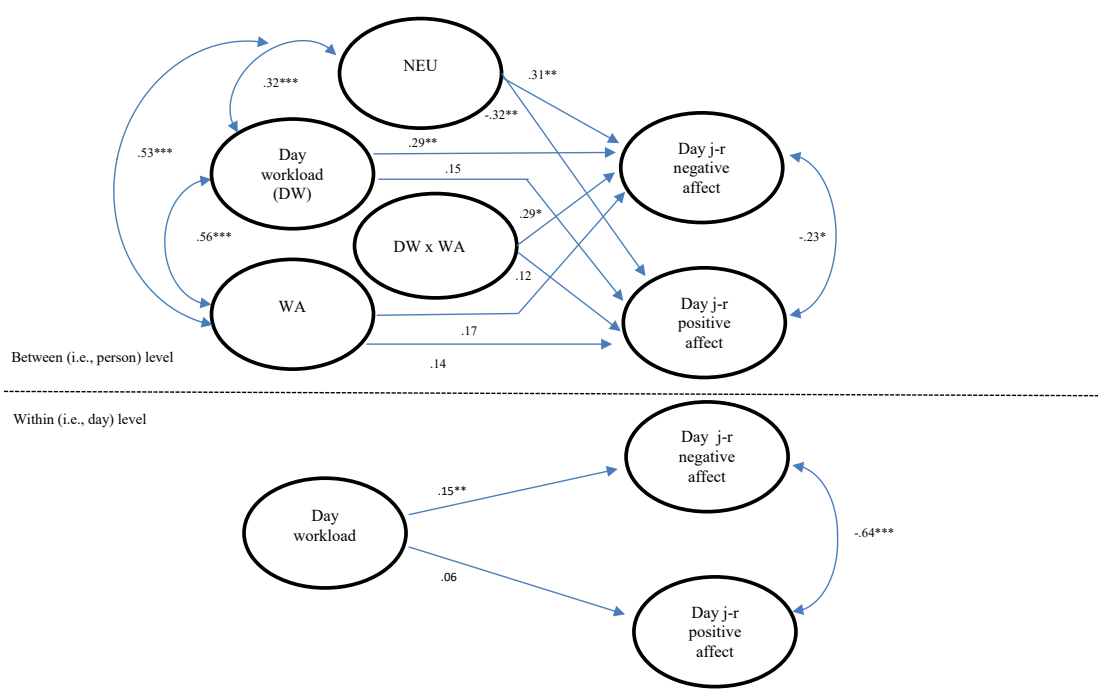

Fig. 2. The 'between' moderated multilevel structural equation model testing for the interaction between work addiction and day workload. Note. Paths are standardized, with exception of the interaction paths, which were only available in unstandardized form in the MPLUS output. WA: Work addiction. j-r: job-related.

$$
{ }^{*} P<0.05 ;{ }^{* *} P<0.01 ;{ }^{* * *} P<0.001
$$

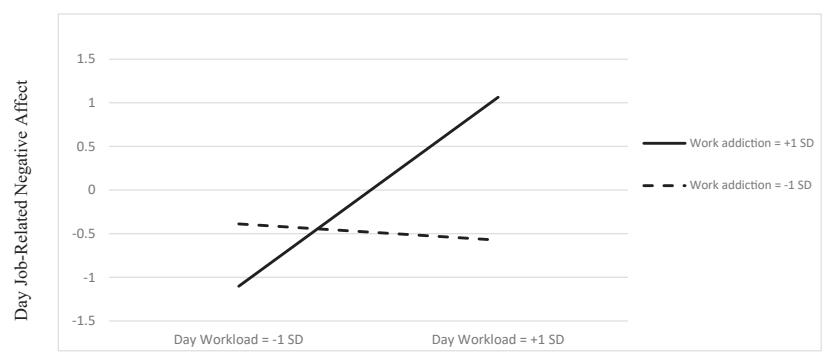

Fig. 3. Representation of the work addiction by day workload 'between' interaction on day job-related negative affect job-related positive affect (Hypothesis 2) could be attributed (at least in part) to neuroticism, a trait affect variable with which work addiction was moderately related in this study.

\section{DISCUSSION}

There has been a long-standing debate regarding the affective nature and experiences that work addicted may commonly undergo at work (Baruch, 2011; Ng et al., 2007; Spence \& Robbins, 1992), and the available studies (see 
Clark et al., 2016) - even the most recent ones (see Balducci et al., 2018; Kirrane et al., 2017) - didn't help to solve the issue. Extending previous research, which was mainly cross-sectional, the present study adopted a daily diary approach, providing a significant and original contribution to the field.

The results of our analyses offered partial support for the study hypotheses, in that work addiction was significantly related to a higher average level of day job-related negative affect, but it was not related to a lower average level of daily job-related positive affect. The results contribute to extant literature by providing evidence that work addicted - in addition to experiencing more accentuated negative affect while not at work - also experience more negative affect while at work. This challenges conceptualizations of work addiction (e.g., Ng et al., 2007) that posit that work addicted experience a respite from the negative emotions (e.g., guilt and anxiety) that they are pervaded with, when they are at work.

The lack of support for the hypothesized negative impact of work addiction on daily job-related positive affect may be due to the fact that such impact is relatively weaker and does not remain identifiable when a trait affect variable (e.g., neuroticism) is included as a control, as it was in our analysis. In any case, our findings suggest that work addiction does not go hand in hand with a higher level of positive affect during working days. This generally diverges from previous research reporting that work addiction relates to work enjoyment (see Clark et al., 2016) or that work addicted derive "particular satisfaction from working hard" (Kirrane et al., 2017, p. 229).

Furthermore, as hypothesized, we also found that experiencing higher levels of daily job-related negative affect acted as a mediator in the relationship between work addiction and end of day emotional exhaustion. On the contrary, positive affective experiences were not related to end of day emotional exhaustion. Overall, these results reveal some elements of a short-term health deterioration process activated by work addiction, with higher end-of-the-day emotional exhaustion being the final outcome of the process. Specifically, sustained load or strain reactions during a stressful workday, which may be the norm rather than the exception for the work addicted, may translate as a slow unwinding after the stressful work period, with symptoms of fatigue and exhaustion being the hallmark signs of such outcome (see Geurts \& Sonnentag, 2006). Slow unwinding, as manifested by higher emotional exhaustion, means a more accentuated need for recovery. Such need for recovery may amplify over longer periods of time, leading to further emotional exhaustion and perhaps to the development of other symptoms of the burnout syndrome, which has often been found to be related to work addiction (Clark et al., 2016).

Thus, our results consolidate previous studies on the work addiction-burnout relationship (e.g., Avanzi et al., 2020; Shimazu, Schaufeli, Kamiyama, \& Kawakami, 2015). Furthermore, our results advance the understanding of such relationship by explaining one of its possible mechanisms an area of inquiry that received little attention in past research (cf. Schaufeli et al., 2009).
Partially in line with what we hypothesized, we also found evidence that work addiction may accentuate the experience of daily job-related negative affect in response to daily workload. Previous research has rarely, if at all, investigated work addiction as a moderator in the stressorstrain relationship (e.g., Clark et al., 2016). Results from the present study provide preliminary support for the idea that high workload may be particularly troublesome for work addicted. One possibility is that because aspects such as poor self-organization, obsessiveness and rigid perfectionism are common in work addiction (see Andreassen et al., 2016; Atroszko et al., 2020), work addicted have significant difficulties in dealing with high workload. The emerged results advance work addiction research by indicating that work addiction may act as a vulnerability factor in distressing work environments, suggesting that work addicted may have a particularly low fit for such environments, at least in terms of stress and well-being.

\section{Implications}

The current study sheds further light on the negative nature of work addiction. The obtained results imply that organizations should have measures in place to safeguard employees against work addiction and its effects. Organizations should increase awareness among employees at all levels that work addiction may go hand in hand with negative workrelated moods and affective experiences (Clark et al., 2016), opening the way to more serious health conditions. Such kind of initiatives should particularly target managers, who are more frequently work addicted (see, for example, Taris et al., 2012) and act as role models of behavior for their subordinates. Secondary and tertiary interventions such as individual counseling, psychological therapy and even referral to dedicated self-help groups such as Workaholics Anonymous may also be needed (see Sussman, 2012).

\section{Limitations and conclusion}

The main limitation of the study is that all the data were selfreported, meaning that the emerged parameter estimates may have been contaminated by common method bias (Podsakoff, MacKenzie, Lee, \& Podsakoff, 2003). However, we neutralized one source of such bias by including neuroticism (i.e., negative affectivity) in the tested model. Moreover, work addiction was measured with a preliminary survey that was temporally separated from the diary surveys with which we measured the mediators and the dependent variable (i.e., job-related affects and emotional exhaustion, respectively). A further potential limitation is that we defined work addiction in terms of working compulsively and working excessively (Schaufeli et al., 2009). It has to be seen whether, by using a different definition and measure of the phenomenon (e.g., Clark et al., 2020), the results of the present study would be replicated. Another issue is the compliance of the participants with the data collection procedure, which may be a concern in paper-and-pencil diary studies such as ours (see Gabriel et al., 2018). Future research could, therefore, implement an electronic daily 
diary study that allows time of completion to be tracked. Finally, we used a convenience sample of participants by focusing mainly on individuals at high risk of work addiction (Taris et al., 2012). This may constitute a threat to generalizability, suggesting the need to replicate our results in future studies.

Despite the above-mentioned limitations, we believe that our study makes a significant contribution to work addiction research. Specifically, we overcame one weakness of work addiction research; that is, the use of cross-sectional designs (see Clark et al., 2016), revealing in a more ecologically valid way (see Kaplan et al., 2013) the prevailing daily job-related affective experiences associated with work addiction. This advances our understanding of the affective nature of work addiction. Additionally, we also provided evidence of a short-term process by which work addiction may affect a crucial component of burnout (i.e., emotional exhaustion), offering one possible explanation for the longterm relationship between work addiction and compromised mental health (see Balducci et al., 2018). Finally, we substantiated the idea that work addiction is a personal vulnerability factor under distressing working conditions, which suggests that work addicted do not thrive in such conditions; rather, they may actually have a particularly hard working life.

Funding sources: Nothing to declare.

Authors' contribution: $\mathrm{CB}$ developed the idea and the design of the study. $\mathrm{CB}$ conducted the analyses and drafted the first version of the study. PS, MC, and LA contributed to writing and revision before submission.

Conflict of interests: The authors have no conflict of interest to disclose.

\section{REFERENCES}

Andreassen, C. S. (2014). Workaholism: An overview and current status of the research. Journal of Behavioral Addictions, 3(1), $1-11$.

Andreassen, C. S, Griffiths, M. D., Sinha, R., Hetland, J., \& Pallesen, S. (2016). The relationships between workaholism and symptoms of psychiatric disorders: A large-scale cross-sectional study. PloS One, 11(5), e0152978.

Andreassen, C. S., Schaufeli, W. B., \& Pallesen, A. S. (2018). Myths about "The myths about work addiction". Journal of Behavioral Addictions, 7(4), 858-862.

Atroszko, P. A., Demetrovics, Z., \& Griffiths, M. D. (2019). Beyond the myths about work addiction: Toward a consensus on definition and trajectories for future studies on problematic overworking. Journal of Behavioral Addictions, 8(1), 7-15.

Atroszko, P. A., Demetrovics, Z., \& Griffiths, M. D. (2020). Work addiction, obsessive-compulsive personality disorder, burn-out, and global burden of disease: Implications from the ICD-11.
International Journal of Environmental Research and Public Health, 17(2), 660.

Avanzi, L., Balducci, C., \& Fraccaroli, F. (2013). Contributo alla validazione italiana del Copenhagen Burnout Inventory (CBI). Psicologia della Salute, 2, 120-135.

Avanzi, L., Perinelli, E., Vignoli, M., Junker, N. M., \& Balducci, C. (2020). Unravelling work drive: A comparison between workaholism and overcommitment. International Journal of Environmental Research and Public Health, 17, 5755.

Baldasseroni, A., Camerino, D., Cenni, P., Cesana, G. C., Fattorini, E., Ferrario, M., et al. (2001). La valutazione dei fattori psicosociali: Il Job Content Questionnaire. Fogli di Informazione ISPESL, 3, 20-30.

Balducci, C., Alessandri, G., Zaniboni, S., Avanzi, L., Borgogni, L., Fraccaroli, F. (2020). The impact of workaholism on day-level workload and emotional exhaustion, and on longer-term job performance. Work \& Stress. https://doi.org/10.1080/02678373. 2020.1735569 .

Balducci, C., Avanzi L., Consiglio, C., Fraccaroli, F., \& Schaufeli, W. (2017). A cross-national study on the psychometric quality of the Italian version of the Dutch Work Addiction Scale (DUWAS). European Journal of Psychological Assessment, 33(6), 422-428.

Balducci, C., Avanzi, L., \& Fraccaroli, F. (2018). The individual "costs" of workaholism: An analysis based on multisource and prospective data. Journal of Management, 44(7), 2961-2986.

Balducci, C., Cecchin, M., Fraccaroli, F., \& Schaufeli, W. (2012). Exploring the relationship between workaholism and workplace aggressive behaviour: The role of job-related emotion. Personality and Individual Differences, 53(5), 629-634.

Baruch, Y. (2011) The positive well-being aspects of workaholism in cross cultural perspective. Career Development International, 16(6), 572-591.

Bentler P. M. (1990). Comparative fit indexes in structural models. Psychological Bulletin, 107(2), 238-246.

Bonebright, C. A., Clay, D. L., \& Ankenmann, R. D. (2000). The relationship of workaholism with work-life conflict, life satisfaction, and purpose in life. Journal of Counseling Psychology, 47, 469-477.

Brevers, D., \& Noel, X. (2015). Commentary on: Are we overpathologizing everyday life? A tenable blueprint for behavioral addiction research: On functional and compulsive aspects of reinforcement pathologies. Journal of Behavioral Addictions, 4(3), 135-138.

Browne, M. W., \& Cudeck, R. (1993). Alternative ways of assessing model fit. In K. A. Bollen, \& J. S. Long (Eds.), Testing structural equation models (pp. 136-162). Newbury Park, CA: Sage.

Clark, M. A., Lelchook, A. M., \& Taylor, M. L. (2010). Beyond the big five: How narcissism, perfectionism, and dispositional affect relate to workaholism. Personality and Individual Differences, 48, 786-791.

Clark, M. A., Michel, J. S., Zhdanova, L., Pui, S. Y. \& Baltes, B. B. (2016) All work and no play? A meta-analytic examination of the correlates and outcomes of workaholism. Journal of Management, 42(7), 1836-1873.

Clark, M. A., Smith, R. W., \& Haynes, N. J. (2020). The multidimensional workaholism scale: Linking the conceptualization and measurement of workaholism. Journal of Applied 
Psychology. Advance online publication. https://doi.org/10. 1037/apl0000484.

Flebus, G. B. (2015). Versione Italiana dei Big Five Markers di Goldberg. Unpublished manuscript. Available online at:https:// docplayer.it/51528201-Versione-italiana-dei-big-five-markersdi-goldberg-giovanni-battista-flebus-universita-di-milanobicocca.html.

Gabriel, A., Podsakoff, N. P., Beal, D. J., Scott, B. A., Sonnentag, S., Trougakos, J. P., et al. (2018). Experience sampling methods: A discussion of critical trends and considerations for scholarly advancement. Organizational Research Methods. Advance online publication. https://doi.org/10.1177/1094428118802626.

Ganster, D. C., \& Rosen, C. C. (2013). Work stress and employee health: A multidisciplinary review. Journal of Management, 39, $1085-1122$.

Geurts, S. A. E., \& Sonnentag, S. (2006). Recovery as an explanatory mechanism in the relation between acute stress reactions and chronic health impairment. Scandinavian Journal of Work, Environment \& Health, 32(6), 482-492.

Goldberg, L. R. (1999). A broad-bandwidth, public-domain, personality inventory measuring the lower-level facets of several five-factor models. In I. Mervielde, I. Deary, F. De Fruyt, \& F. Ostendorf (Eds.), Personality psychology in Europe (Vol. 7, pp. 7-28). Tilburg, The Netherlands: Tilburg University Press.

Griffiths, M. D., Demetrovics, Z., \& Atroszko, P. A. (2018). Ten myths about work addiction. Journal of Behavioral Addictions, $7(4), 845-857$.

Griffiths, M. D., \& Karanika-Murray, M. (2012). Contextualising over-engagement in work: Towards a more global understanding of workaholism as an addiction. Journal of Behavioral Addictions, 1(3), 87-95.

Hakanen, J. J., Peeters, M. C. W., \& Schaufeli, W. B. (2018). Different types of employee well-being across time and their relationships with job crafting. Journal of Occupational Health Psychology, 23(2), 289-301.

Hu, L., \& Bentler, P. M. (1999). Cutoff criteria for fit indexes in covariance structure analysis: Conventional criteria versus new alternatives. Structural Equation Modeling, 6(1), 1-55.

Ilies, R., Dimotakis, N., \& Pater, I. E. (2010) Psychological and physiological reactions to high workloads: Implications for well-being. Personnel Psychology, 63(2), 407-436.

Kaplan, S., Dalal, R. S., \& Luchman, N. (2013). Research methods in occupational health psychology. New York, Routledge.

Karasek, R., Brisson, C., Kawakami, N., Houtman, I., Bongers, P., \& Amick, B. (1998). The job content questionnaire (JCQ): An instrument for internationally comparative assessments of psychosocial job characteristics. Journal of Occupational Health Psychology, 3(4), 322-355.

Kirrane, M., Breen, M., \& O'Connor, C. (2017). A qualitative study on the consequences of intensive working. Human Resource Development Quarterly, 28(2), 227-268.

Klein, A., \& Moosbrugger, H. (2000). Maximum likelihood estimation of latent interaction effects with the LMS method. Psychometrika, 65(4), 457-474.

Kristensen, T. S., Borritz, M., Villadsen, E., \& Christensen, K. B. (2005) The Copenhagen burnout inventory: A new tool for the assessment of burnout. Work \& Stress, 19(3), 192-207.
Lazarus, R. (2006). Emotion and interpersonal relationship: Toward a person-centered conceptualization of emotions and coping. Journal of Personality, 74(1), 9-46.

Lee, R. T., \& Ashforth, B. E. (1996). A meta-analytic examination of the correlates of the three dimensions of job burnout. Journal of Applied Psychology, 81(2), 123-133.

MacKinnon, D. P. (2008). Introduction to statistical mediation analysis. New York: Lawrence Erlbaum Associates.

Maslach, C., \& Jackson, S. E. (1984). Burnout in organizational settings. Applied Social Psychology Annual, 5, 133-153.

Maslach, C., Schaufeli, W. B., \& Leiter, M. P. (2001). Job burnout. Annual Review of Psychology, 52, 397-422.

Maslowsky, J., Jager, J., \& Hemken, D. (2015). Estimating and interpreting latent variable interactions: A tutorial for applying the latent moderated structural equations method. International Journal of Behavioral Development, 39(1), 87-96.

Meier, L. L., \& Cho, E. (2018). Work stressors and partner social undermining: Comparing negative affect and psychological detachment as mechanisms. Journal of Occupational Health Psychology, 24(3), 359-372.

Meijman, T. F., \& Mulder, G. (1998). Psychological aspects of workload. In P. J. D. Drenth, \& H. Thierry (Eds.), Handbook of work and organizational psychology (Vol. 2, pp. 5-33). Hove: Psychology Press.

Muthén, L. K., \& Muthén, B. O. (2015). Mplus user's guide (7th ed.). Los Angeles, CA: Muthén \& Muthén.

Ng, T. W. H., Sorensen, K. L., \& Feldman, D. C. (2007). Dimensions, antecedents, and consequences of workaholism: A conceptual integration and extension. Journal of Organizational Behavior, 28(1), 111-136.

Nie, Y., \& Sun, H. (2016). Why do workaholics experience depression? A study with Chinese University teachers. Journal of Health Psychology, 21(10), 2339-2346.

Peiperl, M., \& Jones, B. (2001). Workaholics and overworkers: Productivity or pathology? Group and Organization Management, 26, 369-393.

Podsakoff, P. M., MacKenzie, S. B., Lee, J. Y., \& Podsakoff, N. P. (2003). Common method biases in behavioral research: A critical review of the literature and recommended remedies. Journal of Applied Psychology, 88(5), 879-903.

Porter, G. (1996). Organizational impact of workaholism: Suggestions for researching the negative outcomes of excessive work. Journal of Occupational Health Psychology, 1(1), 70-84.

Preacher, K. J., Zhang, Z., \& Zyphur, M. J. (2011). Alternative Methods for assessing mediation in multilevel data: The advantages of multilevel SEM. Structural Equation Modeling: An International Journal, 18(2), 161-182.

Preacher, K. J., Zhang, Z., \& Zyphur, M. J. (2016). Multilevel structural equation models for assessing moderation within and across levels of analysis. Psychological Methods, 21, 189-205.

Reid, E., \& Ramarajan, L. (2016). Managing the high intensity workplace. Harvard Business Review, June. Retrieved from https://hbr.org/2016/06/managing-the-high-intensityworkplace.

Schaufeli, W. B., Bakker, A. B., van der Heijden, F. M. M. A., \& Prins, J. T. (2009). Workaholism, burnout, and well-being among junior doctors: The mediating role of role conflict. Work \& Stress, 23, 155-172. 
Schaufeli, W. B., Shimazu, A., \& Taris, T. W. (2009) Being driven to work excessively hard: The evaluation of a two-factor measure of workaholism in the Netherlands and Japan. Cross-Cultural Research, 43(4), 320-348.

Schaufeli, W. B., Taris, T. W., \& Bakker, A. B. (2008). It takes two to tango: Workaholism is working excessively and working compulsively. In R. H. Burke, \& C. L. Cooper (Eds.), The long work hours culture: Causes, consequences and choices (pp. 203205). Bingley, UK: Emerald Group Publishing Limited.

Schaufeli, W. B., Taris, T. W., \& van Rhenen, W. (2008) Workaholism, burnout, and work engagement: Three of a kind or three different kinds of employee well-being? Applied Psychology: An International Review, 57, 173-203.

Shimazu, A., Schaufeli, W. B., Kamiyama, K., \& Kawakami, N. (2015). Workaholism vs. work engagement: The two different predictors of future well-being and performance. International Journal of Behavoral Medicine, 22, 18-23.

Snir, R., \& Harpaz, I. (2012). Beyond workaholism: Towards a general model of heavy work investment. Human Resource Management Review, 22(3), 232-243.

Spagnoli, P., Balducci, C., Fabbri, M., Molinaro, D., \& Barbato, G. (2019). Workaholism, intensive smartphone use, and the sleepwake cycle: A multiple mediation analysis. International Journal of Environmental Research and Public Health, 16, 3517. https://doi.org/10.3390/ijerph16193517.

Spagnoli, P., Haynes, N. J., Kovalchuk, L. S., Clark, M. A., Buono, C., \& Balducci, C. (2020). Workload, workaholism, and job performance: Uncovering their complex relationship. International Journal of Environmental Research and Public Health, 17, 6536. https://doi.org/10.3390/ijerph17186536.

Spence, J. T., \& Robbins, A. S. (1992). Workaholics: Definition, measurement, and preliminary results. Journal of Personality Assessment, 58(1), 160-178.
Sussman, S. (2012). Workaholism: A review. Journal of Addiction Research and Therapy, 6(1), 4210.

Sussman, S. (2018). Ten myths (or facts?) about workaholism: An appetitive motivation framework: Commentary on: Ten myths about work addiction (Griffiths et al., 2018). Journal of Behavioral Addictions, 7(4), 884-887.

Taris, T. W., Van Beek, I., \& Schaufeli, W. (2012). Demographic and occupational correlates of workaholism. Psychological Reports, 110, 547-554.

Taris, T. W., Van Beek, I., \& Schaufeli, W. B. (2014). The beauty versus the beast: On the motives of engaged and workaholic employees. In I. Harpaz, \& R. Snir (Eds.), Heavy work nvestment: Its nature, sources, outcomes, and future directions (pp. 121-138). New York: Taylor \& Francis/Routledge.

Thoresen, C. J., Kaplan, S. A., Barsky, A.P., Warren, C. R., \& de Chermont, K. (2003) The affective Underpinnings of job Perceptions and attitudes: A meta-analytic review and integration. Psychological Bulletin, 129(6), 914-945.

Totterdell, P. A. \& Niven, K. (2014). Workplace moods and emotions: A review of research. Charleston: Createspace Indipendent Publishing.

Vallerand, R. J., Houlfort, N., \& Forest, J. (2014). Passion for work: Determinants and outcomes. In M. Gagné (Ed.), The Oxford handbook of work engagement, motivation, and self-determination theory (pp. 85-105). Oxford, UK: Oxford University Press.

Van Eck, M., Nicolson, N. A., \& Berkhof, H. (1998). Effects of stressful daily events on mood states: Relationship to global perceived stress. Journal of Personality and Social Psychology, $75,1572-1585$.

Van Katwyk, P. T., Fox, S., Spector, P. E., \& Kelloway, E. K. (2000). Using the Job-Related Affective Well-Being Scale (JAWS) to investigate affective responses to work stressors. Journal of Occupational Health Psychology, 5(2), 219-230. 